Journal of Southeast Asian

\title{
Vietnamese American Experiences of English Language Learning: Ethnic Acceptance and Prejudice
}

Jeffrey LaBelle

University of San Francisco, jeffrey.labelle@marquette.edu

Follow this and additional works at: https://docs.lib.purdue.edu/jsaaea

\section{Recommended Citation}

LaBelle, Jeffrey (2007) "Vietnamese American Experiences of English Language Learning: Ethnic Acceptance and Prejudice," Journal of Southeast Asian American Education and Advancement. Vol. 2 : Iss. 1, Article 10.

DOI: $10.7771 / 2153-8999.1125$

Available at: https://docs.lib.purdue.edu/jsaaea/vol2/iss1/10

This document has been made available through Purdue e-Pubs, a service of the Purdue University Libraries. Please contact epubs@purdue.edu for additional information.

This is an Open Access journal. This means that it uses a funding model that does not charge readers or their institutions for access. Readers may freely read, download, copy, distribute, print, search, or link to the full texts of articles. This journal is covered under the CC BY-NC-ND license. 


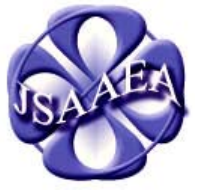

\title{
Journal of Southeast Asian American \\ Education \& Advancement
}

Volume 2

WWW.JSAAEA.org

\section{Vietnamese American Experiences of English Language Learning: Ethnic Acceptance and Prejudice}

\author{
Jeffrey T. LaBelle \\ University of San Francisco
}

\begin{abstract}
This article investigates the effects of ethnic acceptance and prejudice on English language learning among immigrant nonnative speakers. During 2004 and 2005, the author conducted participatory dialogues among six Vietnamese and Mexican adult immigrant English language learners. The researcher sought to answer five questions: (1) What are some nonnative English speakers' experience regarding the way native speakers treat them? (2) How have nonnative English speakers' experiences of ethnic acceptance or ethnic prejudice affected their learning of English? (3) What do nonnative English speakers think they need in order to lower their anxiety as they learn a new language? (4) What can native English speakers do to lower nonnative speakers' anxiety? (5) What can nonnative English speakers do to lower their anxiety with native English speakers? Even though many of the adult immigrant participants experienced ethnic prejudice, they developed strategies to overcome anxiety, frustration, and fear. The dialogues generated themes of acceptance, prejudice, power, motivation, belonging, and perseverance, all factors essential to consider when developing English language learning programs for adult immigrants.
\end{abstract}

In the United States, thousands of women, men, and children continuously confront challenges to their identity and sense of well being as they immigrate and acculturate into the American way of life. In an era of xenophobia, terrorism, and English-only politics, immigrant nonnative English speakers face ever-increasing stress, anxiety, and ethnic prejudice as they strive to become active participants in their new culture (Crawford, 2000). Their collective struggle motivates critical reflection upon immigrants and their experiences of ethnic acceptance and prejudice.

\section{Review of Literature}

In reviewing past research, one quickly discovers that little has been written on the effects of ethnic prejudice on English language learning among immigrants in the United States. In her doctoral dissertation, Shiels (2001) contended that ethnic prejudice is one

\footnotetext{
(C)

SORERIGHISRESERVEDReaders are free to copy, display, and distribute this article, as long as the work is attributed to the author(s) and the Journal of Southeast Asian American Education \& Advancement, it is distributed for non-commercial purposes only, and no alteration or transformation is made in the work. More details of this Creative Commons license are available at http://creativecommons.org/licenses/by-ncnd/2.5/. All other uses must be approved by the author(s) or JSAAEA.
} 
element in a series of factors that can increase enculturation stress. Krashen's research (1985) has suggested that any factor that causes anxiety raises the affective filter of the second language learner. This anxiety results in a slowing or even an interruption in the acquisition of English by nonnative speakers.

The relationship between ethnic prejudice and English language learning might go even deeper. Hirsch (1988) and Unz (NewsMax.com Wires, 2001) continue to contribute to and promote the English-only movement, overtly exhibiting an ethnic prejudice toward immigrant speakers. This prejudice is most evident when the immigrants' nonnative English accent is rejected as inferior or substandard. In sharp contrast to such a position, Canale (1983) dismisses the term "standard" for English speakers, preferring communicative competence as the goal of second language acquisition (SLA). Because of the political sensitivity surrounding terms relating to ethnicity and race, researchers have only recently begun to address this anxiety-causing issue (Macedo, 2000). To what extent does ethnic prejudice impede the acquisition of English by nonnative immigrant speakers in the United States?

Polio and Gass (1998) demonstrated that interaction contributes to a native speaker's comprehension of nonnative speaker's speech. Their study indicated that interaction is essential as a method of improving oral and aural comprehension between nonnative and native speakers of English. Clearly, such interaction is essential to facilitate the language learning process. However, one factor that may impede social interaction between native speakers and nonnative speakers is ethnic prejudice. Besides creating anxiety in the immigrant, ethnic prejudice breaks down the trust, openness, and mutuality that should be part of a healthy, normal conversation (Shiels, 2001). The flow of the interaction is broken and the tension detracts from the natural process that leads to developing communicative competence.

From a sociocultural perspective, Alptekin (2002) asserts that acceptance and tolerance of ethnic diversity are necessary to foster and improve the acquisition of English by nonnative speakers. In a similar way, Schumann (1976) had already posited that, when acceptance and tolerance are lacking, a social distance is created which increases the difficulty of the acculturation and second language learning. In his research, Schumann studied various factors that led to social distancing or proximity in the language learning process, which in turn either promotes or slows the immigrant's acquisition of the target language. Clearly, the quality and intensity of social interaction are essential to effective SLA.

Even though past research has recorded great advances in the interplay between social interaction and SLA, investigation is still lacking that critically reflects upon the experiences of ethnic acceptance and prejudice from the viewpoint of immigrants themselves. In conducting participatory dialogues in Fall 2004 and Spring 2005 with Vietnamese and Mexican immigrants, this researcher documented the critical reflections of six adult immigrants regarding their experiences of both ethnic acceptance and prejudice as well as how these affect their English language learning. Their histories relate how they overcame anxiety and frustration to strive to learn the English necessary to succeed in American society.

Prior to 1975, Mexican immigration dominated the statistics regarding the influx of new immigrants to the San Francisco Bay Area (State of California, Department of Finance, 2001). The official population statistics elucidate a changing blend of ethnic and 
linguistic factors in that particular state. One of several important demographic changes was the upsurge in the Vietnamese population after the fall of Saigon in 1975. These two ethnic groups, Vietnamese and Mexican, provide a unique and fascinating context in which to study factors that affect SLA among immigrants to the United States.

This study examined certain sociological factors regarding the ease in which a nonnative speaker could acquire English. Krashen (1985) pointed to anxiety as a factor that raises the affective filter of the second language (L2) learner. He found that an increased anxiety level in the nonnative speaker resulted in a higher affective filter that blocked the language acquisition process. His hypothesis claimed that, by lowering their anxiety, immigrants could improve and facilitate their language acquisition. Research about factors that lead to anxiety, culture shock, and enculturation stress is extremely useful in promoting English language learning among immigrants (Adler, 1972; Berry, 1987; Krashen, 1985; Shiels, 2001). Hence, this research centers on the effect of ethnic prejudice upon the affective filter of the nonnative speaker.

In the same year of the famous Brown vs. Board of Education decision, Allport (1954) defined ethnic prejudice as "an antipathy based upon a faulty and inflexible generalization” (p. 13). This antipathy is felt, observed, or sensed by the immigrant and, in turn, increases his or her anxiety level. Such prejudice may be directed at a group or individual merely because he or she is of that group. Sometimes ethnic prejudice is overt, but more often it is of a covert nature (Kinder \& Sanders, 1996). In order to uncover the ethnic prejudice experienced by nonnative English speakers, it is advantageous to learn from the participants themselves the nature of this experiential phenomenon.

As more immigrants arrive in the United States, the need for increased attention to issues of SLA becomes more urgent. One particularly sensitive factor in SLA is ethnic prejudice and how it impacts the process of acquiring English among immigrants in general. Further, since many researchers are neither immigrants nor nonnative speakers, it is especially useful to hear nonnative immigrants' own perceptions of the effect of ethnic prejudice on SLA. Such an approach helps promote a wider understanding, acceptance, and openness to varied viewpoints regarding the immigrant experience of adaptation, acculturation, and assimilation into an English-speaking environment.

\section{Methodology}

This study explores immigrants' critical reflections of the way native speakers treat nonnative speakers of English by dialoging with the participants and documenting their experiences of acceptance and prejudice as well as how these factors have affected their learning of English. The researcher chose participatory dialogues as the method of collecting data in order to access the participants' own interpretation of their experiences. The participants themselves reviewed the transcriptions of the dialogues for accuracy and retrospection in follow-up dialogues. Unlike ethnography, participatory dialogues (Ada \& Beutel, 1993) focus the research upon the participants' interpretation of the data rather than the observations or field notes of the researcher. This dialogic methodology was preferred over ethnography in order to give voice to the participants for their own empowerment and conscientization as well as to further the transformation of adult ESL programs. 
The study also investigates, from the perspective of the participants, what native and nonnative English speakers can do to help lower the anxiety for new speakers of the English language. In so doing, native speakers can assist the immigrant to achieve the goal of SLA and communicative competence. It is critical that native English speakers address the issues of ethnic prejudice and cultural conflict if they are to promote the learning of English as a second language among immigrants.

Lippi-Green (1997) asserts that ethnic prejudice is situated within the interaction between nonnative and native English speakers. The dialogues that form the context of this research require a critical approach to unveil the fuller effect of ethnic prejudice on English language acquisition (Freire, 1970). For Freire, all human activity involves theory and practice, as well as reflection and action. Furthermore, he clearly warns that, no one can "unveil the world for another" (p. 169).

By listening to the immigrant's interpretation of his or her experience, we can be conscienticized about the world of the foreigner with all its struggles and complexities (Freire, 1970). These experiences may include the perception of ethnic prejudice based upon foreign accent, skin color, personal hygiene, dress, gestures, and eye contact. In Freire's framework, dialogue plays a key role in the communicative process between teacher and learner. "Only dialogue, which requires critical thinking," claims Freire, "is also capable of generating critical thinking” (p. 92). Native speakers might be well advised to take the posture of a learner in listening to the immigrant and his or her reading of the world of ethnic prejudice. This empowers the participants to interpret how their perception of acceptance and prejudice has affected their own English language learning. It is hoped that this type of dialoguing with immigrants will promote interactive communication that can then lead to greater intercultural understanding.

This research on Vietnamese and Mexican immigrants in Santa Clara County is one example of how the academy can give voice to the participants' own interpretation of their experiences of ethnic acceptance and prejudice, as well as point to the perceived influence these experiences have on their English language learning. By their very interactive nature, participatory dialogues lend themselves to an in-depth examination of factors that increase or decrease anxiety in the participants, possibly contributing to or detracting from the language learning process.

\section{Research Design}

The study employs a qualitative, participatory research design. The researcher audiotaped dialogues conducted in English, transcribed the text, and analyzed them for emerging themes. The participants are six adults, three men and three women, originally from Vietnam and Mexico. These voluntary participants are members of Catholic parishes in Santa Clara County and were accessible because of the researcher's pastoral activity as a Jesuit priest. The initial dialogues were guided by the series of questions to follow that are based upon the general research questions.

The design employed in this study is participatory research, a qualitative method with the key elements of dialogue and critical reflection (Kieffer, 1981). This design entails oral communication in the form of speaking and listening as well as critically reviewing dialogues for further clarification, generating new themes, and strategizing to solve problems. 
Because participatory research is action based, this study involves both the researcher and the participant in a dialogic exchange of ideas regarding a particular concern or problem. The aim of this dialogue is more than the completion of a series of questions and answers. This form of interaction seeks to pose problems and propose solutions based upon the conversations and critical reflections that occur. Ada and Beutel (1993) point out the purpose of participatory research is to create an environment in which people from any walk of life might "become the protagonists in their own life stories” (p. 1).

\section{Questions That Guided the Initial Dialogues}

The following questions were used to guide the initial dialogues. These questions were considered tentative because of the nature of participatory research itself and because of the cultural factors that may require adaptations depending upon the context of the participant. Each set of questions was centered on a specific research question.

Research Question 1: What are some nonnative English speakers' experiences regarding the way native speakers treat them?

Questions: (a) How do you feel when you talk or listen to a native speaker? (b) Can you think of a specific time or situation when you felt accepted and at ease?

(c) What do you think made you feel accepted and at ease? (d) Can you think of a specific time or situation when you were anxious or nervous? (e) What do you think made you feel nervous or anxious? (f) What did the native speaker do to make you anxious?

Research Question 2: How have nonnative English speakers' experiences of ethnic acceptance or ethnic prejudice affected their learning of English?

Questions: (a) What do you call ethnic acceptance? (b) What do you call ethnic prejudice? (c) How do you feel when you observe or experience ethnic acceptance? (d) How do you feel when you observe or experience ethnic prejudice? (e) How has ethnic acceptance affected your learning of English? (e) How about ethnic prejudice?

Research Question 3: What do nonnative English speakers think they need in order to lower their anxiety as they learn a new language?

Questions: (a) How do you want native speakers to treat you? (b) What are some things that might help you feel more at ease as you learn English? (c) How have you overcome anxiety in learning English in the past? (d) What specific things did other people do to make you feel at ease in the past?

Research Question 4: What can native English speakers do to lower nonnative speakers' anxiety?

Questions: (a) Can you recall a specific experience when a native speaker helped you feel more at ease? (b) Can you remember a specific event when you have had a problem with a native speaker that made you feel more nervous or anxious? (c) Can you think of any ways that this situation might have been improved? (d) Of 
the native speakers you know and like the best, what is it that makes you like them? (e) When native speakers make you angry, what is it specifically that they are doing that bothers you?

Research Question 5: What can nonnative English speakers do to lower their anxiety with native English speakers?

Questions: (a) What can you do to help you get along better with native speakers? (b) Can you think of any examples from your own experience that have helped you feel more at ease talking with native speakers?

(c) How do you deal with your nervousness when you talk with native English speakers? (d) What have you done in the past that puts you more at ease in talking with native speakers?

\section{Data Collection}

This section presents the background of each participant as a foundation for the interpretation of the participatory dialogues. Each of the six adults in this study brought their own set of prior experiences, education, family issues, talents, and living situations to the dialogues. These variables contributed to a deeper understanding of the experiences of ethnic acceptance and prejudice related in the participatory dialogues and presented in the findings section. Finally, for validity and authenticity, this section interprets the meaning of these experiences through the eyes of the participants themselves.

The role of the researcher in the present study was to tape record, transcribe, and guide the dialogues, as well as analyze the critical reflections of the six immigrant participants. In addition, the interviewer observed the gestures, demeanor, and environment in which the participatory research occurred. Finally, the participants themselves reviewed the transcriptions of their own dialogues to assure their accuracy and to assist the researcher in verifying and analyzing the data collected.

The researcher conducted three participatory dialogues over a period of six months, from September 19, 2004, to early March 6, 2005. Each recorded session lasted for approximately one hour, for a total of three hours of taped dialogues. In general, the one-hour sessions took place one or two weeks apart to allow time for the researcher to transcribe the taped dialogues as well as for the immigrant and researcher to read over the transcription of the previous session. Because of time limitations on the part of the researcher and the immigrants, only one or two participants could be questioned in a given weekend. This accounts for the number of weeks that it took to conduct the 18 sessions.

On at least four occasions, participants had to cancel appointments and reschedule due to illness, work schedule, or family emergencies. On two occasions the researcher reported to the agreed upon location for a session only to learn at that moment that the participant had to cancel. This caused some frustration and confusion for both researcher and participant, but did not stop the progress of the study. In addition, the researcher was surprised that all six participants responded to the questions that guided the dialogues by the end of the second session. Because of this, after reviewing the transcriptions of the

first two sessions, the researcher composed additional follow-up questions to continue the 
dialogues in the third session. These questions sought to clarify previous dialogues or to interpret the transcriptions of the first two hours of dialogues.

\section{Data Analysis}

By taking the stance of listener or learner, the researcher helped the participants give voice to their experiences of ethnic prejudice and acceptance and how those same phenomena have affected their English language learning. The generative themes uncovered through dialogues and coded in transcriptions revealed common elements present in the six participants' responses. The researcher then analyzed these themes as they relate to ethnic prejudice and acceptance and the English language learning process. Dialoguing with six participants permitted the researcher to listen to diverse immigrant perspectives and critical reflections.

The researcher was limited in regard to differences in his experience of the two ethnic groups in this study. Although he has traveled extensively in Mexico, he has never set foot in Vietnam. In addition, even though the dialogues took place in English, it is important to note that the researcher is fluent in Spanish, but only knows a few phrases in Vietnamese. These differences in cultural experience may have influenced his interpretation of the data presented by the six participants. The researcher may have relied too much on his experience with the Mexican immigrants and obscured the interpretation of their dialogues. In the same vein, he might have misinterpreted Vietnamese immigrant dialogues due to limited previous social interaction with their culture. Therefore, the researcher had to take care to verify his interpretation of the data through the input and review of the participants themselves.

\section{Profiles of the Participants}

The background of each participant serves as an experiential grounding for the findings and interpretation of the data gleaned from the participatory dialogues. These varying backgrounds contribute to a deeper understanding of the experiences of ethnic acceptance and prejudice as related in the participatory dialogues themselves and as presented in the findings section. Finally, the participants themselves helped with the interpretation of the meaning of these experiences through their own eyes, lending an authenticity that only they could give to this study. Because of the focus of this journal is on Southeast Asian Americans, primary attention will be given to the Vietnamese participants in this study, although some contrasts between them and the Mexican participants will be presented in the conclusions and recommendations section. In addition, it should be noted that the three Vietnamese participants in this study emigrated from Vietnam during the free market era (1990-present) in contrast to earlier immigrants from the fall of Saigon or boat refugee eras. The names of the participants below have been changed to maintain confidentiality.

The first Vietnamese participant, Tammy, was born in Saigon, in 1973 while the war was still going on between the north and the south. Tammy could not recall the war herself, but learned of it from her parents and relatives as she was growing up and going to school. She immigrated to the United States with her family in 1994 when she was 21 years old. Her family relocated from Saigon to Salt Lake City, Utah, where their sponsor 
lived. In 2001, Tammy moved to San Jose, California, where she works as a cosmetologist and since 2004 has run her own business in Morgan Hill. She completed high school in Saigon and also attended ESL classes. She studied at junior colleges in both Salt Lake City and San Jose, as well as cosmetology school in both states where she has her certification. Tammy is single, lives with her sister, and participates in the Vietnamese choir group at one of the local parishes in San Jose.

The second Vietnamese participant is a woman named Vivian. She is single, lives in her own apartment, and works as a financial consultant and insurance agent in San Jose, California. She too grew up in Saigon, but moved directly to San Jose in 1996 at the age of 19, after completing her junior year in college. Unfortunately, Vivian had to start her college major all over again, but successfully graduated with her bachelor of science in finance from San Jose State University. Unlike Tammy, Vivian came to the United States after her parents, who themselves had sponsored her and her brother. Vivian attributes her success in finance and business to her accountant father's example and encouragement. She and her fiancé, Duc, were married in the fall of 2005 and live together in San Jose with his parents. Like Tammy, Vivian attended ESL classes both in Saigon and at Evergreen College in San Jose. She joined the Catholic Church last year in preparation for her marriage with Duc. Her brother-in-law, Don, is the president of the choir in which Tammy sings.

The third Vietnamese participant is a man who calls himself Anthony. He emigrated from Saigon in 1994 at the age of 22. Unlike Tammy and Vivian, Tony did not study ESL as a high school student in Saigon, but only later at Evergreen College in San Jose. He is an only child and still lives at home with his parents in San Jose. Tony works two part-time jobs, as an electronic technician for a major Silicon Valley corporation and as a loan officer. Anthony graduated with a B.S. in Management Information Systems in May 2004, from San Jose State University. On weekends, he teaches first communion classes for Vietnamese children at a local Parish in San Jose.

The fourth participant is a Mexican immigrant named Daniel, who lives in East San Jose. Daniel is a certified landscape specialist. He came to San Jose about nine years ago from Guadalajara, Jalisco, Mexico at the age of 19. Daniel has been taking English classes for adults at a nearby High School to improve his speaking ability. Daniel lived for a few years in Oxnard, California, before finally settling in San Jose nearer to his brother. He has not had any formal schooling since high school in Guadalajara, but has learned a great deal of skills during his time in California, from driving tractors, to cotton combines, to forklifts. Later, he worked for a landscaping company and learned the trade as he went. Daniel is energetic, self-motivated, and outgoing. He tries to use his English whenever he can especially when dealing with his landscaping customers.

The fifth participant is a Mexican immigrant named Melanie. Melanie still struggles with her ability to speak English, but enjoys practicing with others. She works as a live-in nanny for a family in Gilroy, and also resides at her sister's home in East San Jose. Melanie earned her bachelor's degree in public accounting in Ciudad Guzman, Jalisco, Mexico, however, she has been unable to use her talents in the field for which she was trained. Only recently has she been able to find part-time work filing in an accounting office. Her goal is to eventually move up in the company to use her talent as an administrator or accountant. 
The sixth participant is a Mexican immigrant named Jimmy. Even though he was born in San Jose, he could be considered an immigrant because his parents moved back to Mexico right after he was born. Jimmy grew up in a small town in the state of Michoacán and came up to San Jose by himself when he was almost 19 years old. He studied for one year at the university level, but decided that job opportunities were better in the United States. Jimmy came up to live with his father's cousins in 1997 and began work for his uncle as an auto detailer. He worked his way up eventually to become an automotive technician. Jimmy has moved frequently in the San Jose area for the last eight years. He speaks English quite well and has his automotive technician certification after studying at both San Jose City College and De Anza College.

\section{Findings and Interpretation}

The findings and interpretation of the data in this study are organized according to the five research questions. Although the data collection from the participatory dialogues was guided by these questions, other generative themes surfaced during the retrospective dialoguing that took place in the third participant dialogue sessions. These data are presented separately from the other five categories because they points directly to conclusions and recommendations for further research. Although the study included six participants, the focus of this paper will be on the three Vietnamese participants. However, some discussion of the themes and issues which were common among both the Vietnamese and Mexican immigrants will be included in the findings.

\section{Research Question 1: What Are Some Nonnative English Speakers' Experiences Regarding the Way Native Speakers Treat Them?}

The predominant experience of the six participants in this study was very positive regarding how they were treated by native speakers. Essential to this positive quality of their experiences were the patience, openness, and receptivity of the native speakers who conversed with them. Vivian stated this very succinctly about her native speaker friend from Evergreen Valley College, "Yeah, he’s kind of like really open-minded.”

Nevertheless, each of the six participants also related experiences that were negative, humiliating, demeaning, and even frustrating. Some of them experienced such poor treatment that they were saddened, felt put down, or depressed. These experiences were often associated with the workplace or other public venues. Vivian narrated an encounter with an angry customer who drove her to tears because of her inflammatory comments about Asians in general. She recalled vividly, "And she yelled at me. She said, 'You know, you Asians, just go back to your country! You don't know what you're doing! What you doing here? I don't like to see all the Asian people here!'”

The various participants attributed different factors as the cause of their anxiety or comfort when conversing with native English speakers. The most prevalent of the anxiety causing factors was foreign accent. Vivian put it this way, "And I understand them. And sometimes they understand me, but sometimes they don't, because I have an accent." The participants themselves identified and interpreted the importance of foreign accent in their communicative competence in English. However, most recognized that accent was an enduring reality in their nonnative English speaking. Still, they concluded that English 
learning is a life-long process that can diminish the presence of a nonnative accent, but never eliminate it.

On another front, the participants all stressed the importance of building friendships with native English speakers. The six participants recognized that their comfort level increased when they practiced their English with a friendly native English speaker. Sometimes the participants met these new friends at the junior college, other times in the workplace. In either context, they all cited increased confidence and comfort when speaking with new native speaker friends. Among all the participants, Vivian was most articulate when she related, “So, that's the way I'm comfortable to talk to him, because he not laugh about my accent. He not laugh about my tradition or anything like that." Fortunately, she and the others met native speakers of English who exhibited acceptance and understanding with them as immigrants.

In spite of these positive experiences of ease in speaking English, several of the participants cited occasions, especially in their early learning, in which they felt nervous, afraid, threatened, or frustrated. All of these emotional upheavals led to increased anxiety, resulting in the raising of their affective filter. In fact, all of the participants echoed this same uneasiness at error correction. They preferred a more patient, subtle, suggestive style of correcting or guiding when absolutely necessary for communicative competence.

Of course, the participants' desire for acceptance or comfort when interacting with native English speakers led them to seek out acquaintances and friendships that provided opportunities for dialogue. Sometimes, ESL instructors provided this source of a supportive dialogue partner. Anthony recalled one such experience with his ESL professor at Evergreen Valley College, "I tried to ask many questions. I tried to have a chance to speak English with her." This self-initiative served him and the other participants well as they sought to enter into conversations with more native English speakers. Their effort to reach out to others in order to learn English better in turn built their self-confidence and poise as new English speakers.

\section{Research Question 2: How Have Nonnative English Speakers’ Experiences of Ethnic Acceptance or Ethnic Prejudice Affected Their Learning of English?}

All six participants struggled to understand the concepts of ethnic acceptance and ethnic prejudice. It became clear in the course of the participatory dialogues that the participants were unfamiliar with the terminology central to the study. However, by dialoguing and recalling personal experiences, each participant came to a better understanding of the meaning of these two factors. In short, the dialogues themselves served to help the participants reflect upon their experience and gain a better understanding of how both ethnic acceptance and ethnic prejudice had been present in their personal histories.

Experiences of ethnic acceptance can certainly help foster a sense of trust and confidence in the individual immigrant. All three Vietnamese participants remembered many situations in which they felt accepted by native speakers. These supportive interactions served as a turning point in their English language learning to foster within them a sense of reassurance, belonging, and success. Anthony exemplified this when he concluded, "I'm lucky because most of the people I met, they are so friendly.” Tammy 
illustrated this further, “I think that's the distance between us. So I don't talk. They kind of turn me off. But there's some people they're very friendly and they ask questions and then that's, I think we're getting a little closer."

In some cases the encounters of ethnic acceptance took the form of friendships. In other instances the participants recalled supervisors or mentors at work who provided the kind of support and encouragement needed to motivate them to learn more English. As Tammy clarified so well, "And I really appreciate what my mentor he did for me. He's a very nice guy. He explained to me everything every detail." Many times over the participants recounted in detail the positive experiences of native speakers who had helped them, accepted them, and encouraged them to make even greater efforts to learn English. All the participants valued the effect these native speakers had on them as English language learners.

The influence of ethnic acceptance can run even deeper, to touch the very selfidentity of the immigrant. Vivian recalled some cases of ethnic prejudice, but still surmised:

So, that's what I want: more acceptance. I want to be accepted more because I've been working on that. I want people to be accepting me for who I am, not because I’m speaking English good or something like that.

Much like the others in the study, she needed to overcome bad experiences as well. Vivian's bold statement is echoed in Tammy's proclamation:

When I do an American customer, sometimes I cannot speak well and I cannot explain all the advice for customers when they ask me. But I really appreciate for those people, they accept me as the cosmetologist and they keep coming with me. They accept me as, for who I am. They trust my ability to do for them even though I cannot speak very well in English.

In fact, all six participants in the study sought the same kind of acceptance that in turn fostered a sense of self-worth, self-identity, and confidence.

Tammy had a unique workplace experience of ethnic prejudice. When she was studying at the cosmetology school in San Jose, along with other Vietnamese women, her instructor became very indignant when they were speaking in their native language instead of English. Tammy recounted vividly: "And he walked by and he said, "You cannot speak Vietnamese here, okay? You have to speak English! You have to speak English! No Vietnamese here." She and her colleagues then switched to English out of fear of the instructor. At the time, Tammy felt afraid, hurt, and angry. It was only later, after reflecting, that she could reinterpret this experience in another light.

Nevertheless, the six participants insisted that they were able to overcome these negative experiences and turn them around for their own good in learning English. Vivian concluded, “But when you've been prejudiced, I'm thinking I need to learn more to be fluent in English so maybe they can change their mind about me." For her, the unpleasant, discomforting encounters of prejudice serves as a motivation to make even more effort to learn English well. In fact, all six participants cited instances of this same phenomenon in each of their lives. 
Anthony interpreted these events as personality issues more than ethnic issues. He was able to overcome experiences of ethnic prejudice by forgiving the native speaker much as he would forgive any other person. "I'm a person to forgive easily. Yeah, I don't know why. I just forgive.” Tammy reinterpreted her cosmetology instructor's reprimand to speak English only as a boon to practicing her English. "I appreciate that because if he didn't say that, we'd still be talking Vietnamese. So, we cannot practice English well.”

\section{Research Questions 3: What do Nonnative English Speakers Think They Need in Order to Lower Their Anxiety as They Learn a New Language?}

The participants related many techniques that might assist nonnative English speakers to lower their anxiety. These methods included such simple tools as not interrupting, giving cues or hints, listening, being patient, and speaking slowly on the part of the native speaker. Tammy highlighted these by stating, "don't interrupt them in the middle of the conversation. Just let them finish the talking, and then you can ask them again.” In general, the six participants in the study tended to refer to what the native speakers could do rather than what they themselves might attempt to lower their anxiety.

However, a few pointed out that the nonnative speakers must make an effort to work through their anxiety and try to speak the best they can. As Anthony expressed "If I stay home, I just read the newspaper, it's just, it's not enough.” To lower their anxiety, the participants need to take a risk, even if it means making mistakes. Still, with the support and encouragement of native speakers, the nonnative speakers will be more at ease to accept correction and guidance.

Even so, when all else fails to lower their anxiety, the nonnative English speakers must draw from other inner resources. At times, the participants simply told about the need to patiently wait until they could grasp what they were hearing in English. Clearly, because language is dialogic by its nature, these new English speakers, as well as the native speakers they met, played a role in lowering the tension or anxiety of an encounter. The native speakers needed to pay attention, the nonnative speakers could use more patience, and both participants in the conversation would do well to ask clarifying questions when they do not understand.

Another attribute that some of the participants identified was open-mindedness. Several contended that, if they were open to new possibilities, they would feel less threatened or anxious about things in general. Some viewed openness to learning English and experiencing a new culture as essential to adapting and making progress as a person. Vivian echoed this sentiment when she concluded, "So, you need to treat others as equal.”

All the participants wanted to fit or belong in the new culture in order to feel more comfortable and less anxious. Although they also commented on how they were affected by the way the native speakers treated them, it was Anthony who turned the question around on the researcher, "How would you like Vietnamese people to treat you? Respect, and honesty. Friendly." Hence, mutuality and equality in social interaction can provide a sense of ease and comfort for the nonnative English speaker. Vivian warned, "Don't look at me, because I'm Asian or because I'm poorer than you or because I'm richer than you. Just treat me equal. That's what I want. That they trust me.” 
Some of the participants believed that native speakers could engender a selfconfidence and pride among nonnative English speakers. By collaborating and mixing with native speakers, Anthony indicated, "When the people know each other, they treat each other better."

\section{Research Question 4: What Can Native English Speakers do to Lower Nonnative Speakers' Anxiety?}

The participants most frequently mentioned the importance of listening as a characteristic that would help lower their anxiety. Each of the participants perceived this in his or her own way, such as facial expressions, encouraging tone, and patient or polite choice of words. Tammy summarized, "It's just the way that they open the conversation and make me feel comfortable to talk to them." She and the others inferred a posture of listening on the part of the native English speakers through their own observations of a wide variety of cues, verbal and nonverbal.

Another experience shared by several of the participants was the verbal encouragement from native English speakers. Tammy reminisced, "And he said, 'Oh you speak English very well!' And I think that's the way they encourage me to learn English more even though I still have the accent." And she was not alone in cherishing this type of recognition. Anthony looked back upon his years at Evergreen Valley College with joy and pride when Mrs. Rucker presented him with a literary prize. "But she give me the, the paper, the prize, congratulations, and the book with, with my name. The book, in, in the magazine there's my story. I still keep the book with me." He interpreted this experience as an incentive to continue striving to learn more English, as much and as well as he could.

All of the participants recognized the importance of interacting with native English speakers as the best way to become more comfortable in English. Clearly they each came to the realization that dialoguing with native speakers was the most natural and effective way to achieve a level of spoken English that was comfortable for them. Tammy insisted, "Because I'm thinking, if I do my part and they don't do their part, it's not gonna help by itself. It's not one-way.” The responsibility to communicate lies with both the native and nonnative speaker alike. The communicative burden is shared by both listener and speaker in the social interaction between immigrant and native English speaker (Lippi-Green, 1997). For Tammy, the failure to interact will result in her isolation and the limitation of speaking her native Vietnamese only.

\section{Research Question 5: What Can Nonnative English Speakers do to Lower Their Anxiety With Native English Speakers?}

Many of the participants cited perseverance as the key to overcoming anxiety in speaking with native English speakers. Early in their learning of English, all six participants in the study experienced setbacks, obstacles, frustrations, and traumas that produced a great deal of nervousness and anxiety. However, all of them underscored the effort they had to make in order to move beyond these hurdles. This type of resilience or self-motivation became crucial for the participants to move on from experiences of ethnic prejudice to 
later enjoy the more predominant situations or events that reflected ethnic acceptance. An immigrant needs to make the effort as Vivian suggested, "You have to reach out."

In addition, some of the participants recommended patience, poise, and relaxation as ways to overcome anxiety in dealing with native English speakers. They pointed to patience with one's errors, poise or self-confidence to correct and accept correction, and relaxation to settle the nerves. Anthony preferred to meet with native English speakers in person because phone conversations are more anxiety-provoking. In some cases, avoiding or postponing encounters with difficult people might prove useful in reducing anxiety. Anthony remembered, “And many people they're so difficult to get along. I just stay away from them."

Although their personalities varied greatly, the participants recognized that they had to confront their own fear, anger, and sadness. Tammy phrased it this way, "even though we are Vietnamese, I'm Vietnamese or you are American, or other people's African, but we are still humans.” Anthony liked to think of these difficulties as personality differences that can cause anxiety due to a particular style of relating and not because of the ethnic differences between him and the native English speaker. Vivian said, "You know, if you correct it nicely, I'll continue with you." In short, the participants suggested that the human factor must be taken into account in order to recommend means of reducing anxiety.

Finally, the participants in the study emphasized the importance of effort on their part to relate to other English speakers. Vivian summarized, "Um, communicate. Talk. Make friends to not like native Americans, but other foreigners who come to live in America too." Of course, this means finding those individuals who will be supportive and enter into the dialogue. Tammy encouraged nonnative English speakers, "I would find some friends or someone they can be my teacher, or they can be like a good friend. And I keep talking with them." Still, even this requires effort on the immigrant's part as well as patience and acceptance on the part of the native English speaker.

\section{Conclusions}

Ethnic acceptance and ethnic prejudice are experiences common to many immigrants. These experiences can be sources of frustration and anxiety on one hand or motivation and determination on the other (Berry, 1987). Successful immigrants overcome their fear and anxiety by making friends with native and nonnative speakers alike. Furthermore, they have to step out of their comfort zone to achieve greater communicative competence (Hymes, 1964; Vygotsky, 1978). Indeed, listeners and speakers alike bear the burden of communication together (Lippi-Green, 1997). On the one hand, immigrants must be responsible for taking the initiative to attempt to speak English. On the other, native speakers must learn strategies for listening and understanding, accepting and reinforcing the nonnative speakers (Polio \& Gass, 1998)

Among the participants in the study, the Vietnamese participants expressed a drive to learn English even though they experienced some incidents of prejudice. The three of them had an approach to life that focused on the positive aspects rather than the negative. All of the Vietnamese participants believed they could block the experience of ethnic prejudice out of their minds. They felt they could concentrate their energy on learning English as a means to belong in the American culture. 
One possible factor that may have led to the difference between the approaches of these two ethnic groups is the variation in the distances that separate them from their homelands. Since Mexico borders on California, the Mexican participants fostered nostalgia and a possibility of returning to their home towns one day, either for visits or for good. The Vietnamese participants all expressed their acceptance and appreciation of America as their new country and culture. They all would like to go back to visit Vietnam one day, but never to return permanently. Of course, such a trip would entail a greater expense in time and money than the Mexican participants.

All of the participants experienced both ethnic acceptance and ethnic prejudice. Most often, however, the predominant experiences were positive and accepting. Successful immigrants overcome their fear and anxiety by making friends with native and nonnative speakers alike. Furthermore, they have to step out of their comfort zone to achieve greater communicative competence. Listeners as well as speakers bear the burden of communication together. Immigrants must be responsible for taking the initiative to attempt to speak English. Native speakers must learn strategies for listening and understanding, accepting, and reinforcing the nonnative speakers. America is seen as a place of freedom and opportunity by the participants in the study. Immigrants and natives alike can be accepting or prejudiced.

\section{Generative Themes}

Some topics surfaced naturally during the course of the participatory dialogues. A few of these themes were rather unexpected in nature. Others were simply further developments of the questions to guide the initial dialogues. In either case, such generative themes were artifacts of the participants themselves as they strove to read their world, to interpret their experiences with a more critical consciousness. Rather than stifle these seemingly tangential themes, the researcher chose to give them voice, to encourage their elucidation. Ultimately, these same generative themes reinforce the participatory nature of the study and give due recognition to the authority of the participants themselves as the best source of knowledge and critical analysis of their experiences.

\section{Acceptance}

Although all six participants had a general sense of the meaning of acceptance in their lives, none of them clearly connected this acceptance to issues of ethnicity. By unveiling this aspect of acceptance with them, the researcher guided the dialogues to look more deeply into the full nature of acceptance in their new cultural milieu of the United States. The participatory dialogues probed more intensely into the meaning of experiencing ethnic acceptance as a means of lowering anxiety and heightening motivation to acquire English. To a great extent, the social interaction between the researcher and the participant encouraged a retrospective look at how profound the experiences of each participant were in relationship to his or her sense of self-worth, self-confidence, and self-motivation. In brief, for the participants, ethnic acceptance really refers to people being accepted for who they are, for their culture. 


\section{Prejudice}

In the process of guiding the participatory dialogues, the researcher became keenly aware that the term ethnic prejudice was new to most of the participants. Because of this, a great deal of dialogue time was spent in clarifying and discussing the meaning of this term and how the participants interpreted its role in past experiences. Even further, this effort provided an opportunity for each immigrant to grow in his or her self-awareness and ability to critically reflect upon negative experiences from the past. Many of the participants viewed their accent as a reason why some native speakers demonstrated signs of ethnic prejudice towards them because it was a clue to their foreignness. Others pointed to the blame associated with merely being from another country as the core of ethnic prejudice. In short, they saw themselves as an easy target for discrimination and finger pointing. In essence, this particular generative theme gave rise to a new consciousness among the participants regarding the impact these experiences have made in their lives as nonnative English speakers.

\section{Power}

Several of the participants discussed their experiences of powerlessness during the dialogues. The participants perceived that they were treated as less than native speakers at times. They pointed out ways in which others presumed that they were not educated because they could not speak English without an accent. This type of treatment often resulted in frustration and sometimes even anger on the participant's part. Tammy captured this feeling of desperation best when she related:

And I want, like, native Americans to pay attention about Vietnamese because in a way, we're feeling like we don't have a voice yet in the society because we're just fugitives. Look at that, we don't have much of a voice. And you know, sometimes, we feel like we're not belonging to, you know, this society because we have no power, we have no voice to talk.

The participants all expressed their hope that this research would be a voice for all immigrants who struggle to learn English, who long to be fully accepted members of American culture and society.

The language power play tilts in favor of the native speaker. The participants' frustration was palpable when they recollected experiences of this type of disempowerment.

\section{Motivation}

The six participants in this study all recognized the importance of encouragement and motivation in learning English. Living in the ethnically mixed neighborhoods of San Jose, they felt an obligation to learn English in order to communicate with people of many countries of origin. In ESL classes, they encountered a great variety of ethnic groups, all striving to become competent in the speaking of English. Both the Vietnamese 
and the Mexican participants viewed this as a motivation or reinforcement because they recognized they were not alone in studying English. In fact, one Mexican and one Vietnamese participant commented that they felt they had an easier time of it than some other ethnic groups because their home languages use the Roman alphabet and have many sounds in common with English.

\section{Belonging}

Part of the challenge of learning a new language is adjusting to the new culture in which one lives. The participants recognized the importance of fitting in with their coworkers, classmates, and neighbors as a way to achieve a sense of belonging. Naturally, each of the participants in the study related stories of the difficulties of arriving in the United States. Once here, they were confronted with even more challenges, new customs, values, and beliefs. Vivian found that conversing with other immigrants from different countries helped them feel more a part of the new culture. Tammy valued the learning of English as a way to acquire a sense of belonging. All of these experiences of belonging, acceptance, and trust fostered the participants' feelings of comfort and ease, essential elements in facilitating their learning of English.

\section{Perseverance}

This final theme of perseverance recurred with great frequency during the participatory dialogues. The participants all expressed the opinion that individual effort and perseverance are keys to progress in acquiring English. Vivian insisted that by confronting her nervousness, by facing it, she could overcome it. Certainly, it helped many of the participants to have enough friends, both native and nonnative speakers, with whom they could practice their English. For all of the participants in the study, the key was to take action, to reach out, to not give up regardless of the experiences of prejudice they might encounter.

\section{Recommendations for Practitioners}

The six participants offered a series of recommendations during the course of the participatory dialogues. These suggestions are grounded in their experiences of struggling to learn English and are a result of critical reflection. Since these same language acquisition techniques have proven useful for them individually, the participants expressed the hope that they might also help other immigrants in the future. These recommendations are by no means exhaustive, but represent the suggestions that the participants voiced themselves. However, these recommendations by no means should be considered as strategies that will necessarily succeed in all ESL context.

\section{Mixed ESL Groupings}

One useful recommendation from the participatory dialogues was the mixing of immigrants from different countries of origin in ESL classes. The participants felt that 
this would promote the use of English among the conversation groups as the only means of communicating effectively. The participants had experienced ESL groups of their ethnic peers that had resorted to conversing in their home language instead of the target language. The simplest and most effective corrective for this would be to ensure that different ethnic groups are represented in each ESL conversation group.

\section{Closed Captions Reading Methodology}

The participants found using closed captions when watching English language television to be a useful tool to help them with their reading of English as well as with their aural comprehension. Perhaps during the first year of practicing English the ESL students could make use of this tool to transition to oral English television viewing. The captioning might serve to lower anxiety and assist in the comprehension of new words and sounds (Krashen, 1985). This increased input will promote the production of new English output at a later time.

\section{Listening Skills}

The shared communicative burden not only applies to speaking, but also listening. The participants all expressed the need for native speakers to take the time to listen to them. Some of the participants encountered native speakers who rushed them, interrupted them, or did not have the patience to ask questions. All of these are part of listening actively to the nonnative speaker. Some of the participants welcomed correction by native speakers, especially if this was done in a supportive, interactive atmosphere. Native speakers need to develop an ear for the dialectal variations among immigrant groups that live in their neighborhoods in order to communicate effectively. The participants suggested that, with practice, with patience, and with understanding, the dialogues between them and native speakers could be more conducive toward their goal of communicative competence.

\section{Native Speaker Friends}

Several of the participants have developed long-lasting friendships with native speakers. These types of friends are extremely helpful to those who want to learn English. On one level, they provide the type of nurturing, supportive environment which helps lower the affective filter of the nonnative speaker. Further, such friendships provide numerous opportunities to practice speaking English and to develop better aural comprehension. Building trust between friends can also allow for appropriate correcting of language errors. Finally, the self-confidence engendered in friendships with native speakers helps empower the nonnative speakers to venture outside of their comfort zones and deal with more difficult situations that may arise in the workplace or neighborhood.

\section{Workplace ESL}

Several of the participants and their family members have benefited from ESL classes of various types. Some have even had classes provided by their employers. Because of their age and level of education, many immigrants would be well served to have ESL classes 
right in their places of employment. Employers would benefit from increased productivity, morale, and efficiency among immigrant workers. The more comfortable the employee is with speaking English with native speakers, the happier and more communicative he or she will likely be.

\section{Cultural Survival Techniques}

The Vietnamese and Mexican participants in this study enjoy the comfort of their own language, customs, and beliefs. These newly arrived nonnative speakers find a comfort zone in their homes, churches, and ethnic businesses. Fellow immigrants can help one another in the process of adapting to the local culture and language. In general, in the Santa Clara Valley, most of the goods and services needed by Vietnamese immigrants are available in their home language. These familiar ethnic elements can buffer the impact of the transition and help to lower the anxiety nonnative speakers feel when confronted with a new language and culture. Nevertheless, individuals must take the initiative to venture outside their comfort zone to make progress in learning a second language.

\section{Limitations and Recommendations for Further Research}

Because this study includes only six participants, the findings cannot be generalized to all immigrant Vietnamese or Mexicans in any quantitative way. Still, among the backgrounds of the participants in these dialogues, a diversity of educational experiences was evident. Vivian and Tammy benefited from ESL classes in Vietnam, while Anthony did not have this advantage. The two women participants questioned the usefulness or quality of the ESL programs in their home countries. Vivian recalled her frustration when she was informed that her university degrees were not valid in the United States. All of these various experiences suggest the need for ESL teachers of Vietnamese students to have a greater awareness of the educational systems in Vietnam to better understand the funds of knowledge that the participants bring with them to the United States (Moll, 1992). Their life experiences, education, and family upbringing are all factors to be considered in planning ESL classes here in the United States. Such research might shed light on common texts, methods, and program designs in order to make the transition to the new culture and language smoother and more pedagogically effective.

In addition, further research would be helpful about the differences in SLA among the Vietnamese immigrants who arrived in different eras, for example, war refugees, boat people, and open market emigration. In the course of the participatory dialogues, the Vietnamese participants categorized their experience of immigration as different from those who fled during the Vietnam War and those who escaped clandestinely. The three adult Vietnamese in this study considered themselves open market or free immigrants because they were sponsored by relatives and arrived by commercial jet after changes in the policy of the Vietnamese government. More research is needed regarding the methods of ESL that might be most effective and useful with each of these waves of Vietnamese immigrants. 


\section{References}

Ada, A., \& Beutel, C. (1993). Participatory research as dialogue for social action. Unpublished manuscript, University of San Francisco.

Adler, P. S. (1972). Culture shock and the cross-cultural learning experience. Readings in Intercultural Communications, 2, 6-12.

Allport, G. (1954). The nature of prejudice. Cambridge, MA: Addison-Wesley.

Alptekin, C. (2002). Towards intercultural communicative competence in ELT. ELT Journal, 56(1), 57-64.

Berry, J. W. (1987). Acculturation and psychological adaptation: A conceptual overview. In J. W. Berry \& R. C. Annis (Eds.), Ethnic psychology: Research and practice with immigrants, refugees, native peoples, ethnic groups and sojourners (pp. 4152). Berwin, PA: Swets North America, Inc.

Canale, M. (1983). From communicative competency to communicative language pedagogy. In J. Richards \& R. Schmidt (Eds.), Language and communication (pp. 2-27). London: Longman.

Crawford, J. (2000). At war with diversity: U.S. language policy in an age of anxiety. Clevedon, UK: Multilingual Matters.

Freire, P. (1970). Pedagogy of the oppressed. New York: The Continuum Publishing Company.

Hirsch, E. D., Jr. (1987). Cultural literacy: What every American needs to know. New York: Vintage.

Hymes, D. (Ed.). (1964). Language and culture in society: A reader in linguistics and anthropology. New York: Harper \& Row.

Kiefer, C. (1981). Doing “dialogic retrospection:” Approaching empowerment through participatory research. Paper presented at the International Meeting of Society for Applied Anthropology, Edinburgh, Scotland, University of Edinburgh.

Kinder, D., \& Sanders, L. (1996). Divided by color: Racial politics and democratic ideals (American politics and political economy). Chicago: University of Chicago Press.

Krashen, S. (1985). The input hypothesis. London: Longman.

Lippi-Green, R. (1997). English with an accent: Language, ideology, and discrimination in the United States. New York: Routledge.

Macedo, D. (2000). The colonialism of the English-only movement. Educational Researcher, 29(3), 15-24.

Moll, L. (1992). Funds of knowledge for teaching: Using a qualitative approach to connect homes and classrooms. Theory into Practice, 31(2), 132-141.

NewsMax.com Wires (2001, June 16). Ron Unz exposes folly of bilingualism. United Press International. Retrieved April 10, 2004 from http://www.newsmax.com/archives/articles/2001/6/5/155101.shtml

Ogbu, J. (1991). Low school performance as an adaptation: The case of Blacks in Stockton, California. In M. Gibson \& J. Ogbu (Eds.). Minority status and schooling: A comparative study of immigrant and involuntary minorities (pp. 249285). Mahwah, NJ: Lawrence Erlbaum Associates.

Polio, C. G., \& Gass, S. M. (1998). The role of interaction on native speaker comprehension of nonnative speaker speech. The Modern Language Journal, 82(3), 308-319. 
Schumann, J. (1976). Social distance as a factor in second language acquisition. Language Learning, 26(1), 135-143.

Shiels, K. (2001). A qualitative analysis of the factors influencing enculturation stress and second language acquisition in immigrant students. Unpublished doctoral dissertation, Wilmington College, Wilmington, Delaware.

State of California, Department of Finance. (2001). Selected racial groups and specific origin of Hispanic or Latino. Sacramento, CA: California Census Data Center.

Vygotsky, L. S. (1978). Mind in society. Cambridge, MA: Harvard University Press.

\begin{abstract}
About the Author
Father (Fr.) Jeffrey T. LaBelle, S.J., completed his term in Spring 2007 as an assistant professor in the International and Multicultural Education Department of the University of San Francisco. In August 2007, he will assume a tenure-track, assistant professor position at Marquette University's School of Education in Milwaukee, Wisconsin. Fr. LaBelle holds a BA in InterAmerican Studies with emphasis in Spanish and ESL from the University of the Pacific. As part of his training for the priesthood, he earned Master of Divinity and Master of Theology degrees from the Jesuit School of Theology at Berkeley. He completed his EdD in International and Multicultural Education from the University of San Francisco in 2005. Fr. LaBelle's teaching and research interests focus on sociolinguistics, multicultural education, and immigrant English language acquisition. Prior to teaching at the university level, Fr. LaBelle served for twelve years in two different Catholic parishes in San Jose, California, where he was involved in extensive pastoral work among immigrants from Latin America, Vietnam, and the Philippines. Fluent in Spanish for over 30 years, Fr. LaBelle has also taught ESL and Spanish at secondary schools in California and Peru.
\end{abstract}




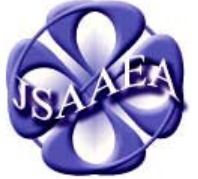

Journal of Southeast

\section{Education \& Advancement}

Volume 2

\author{
WWw.JSAAEA.org
}

\section{Editor}

Dr. Wayne E. Wright

University of Texas, San Antonio

\section{Associate Editors}

Dr. Chhany Sak-Humphry

University of Hawaii

Dr. KimOanh Nguyen-Lam

California State University, Long Beach

Book Review Editor

Dr. Leslie Turpin

School for International Training

\section{Creative Works Editor}

Phouang Hamilton

Washington Office of Superintendent of Public Instruction

\section{Special Advisor}

Anne Frank

University of California, Irvine, Southeast Asian Archives

\section{Editorial Assistant}

Shereen Bhalla

University of Texas, San Antonio
A peer-reviewed

scholarly journal published by the

National Association

for the Education \&

Advancement of

Cambodian, Laotian,

and Vietnamese

Americans (NAFEA)

Comments and questions for the editorial staff may be directed to jsaaea@lists.sis.utsa.edu.

\section{Editorial Review Board}

\author{
Dr. Carl L. Bankston III \\ Tulane University \\ Dr. Pollie Bith-Melander \\ San Jose State University \\ Dr. Phala Chea \\ Lowell Public Schools \\ Dr. George Chigas \\ University of Massachusetts, Lowell
}

\author{
Dr. Changming Duan \\ University of Missouri, Kansas City \\ Dr. Sophal Ear \\ Syracuse University
}

\section{Dr. Nancy H. Hornberger} University of Pennsylvania

Dr. Samlong Inthaly Minneapolis Public Schools 


\author{
Dr. Peter Nien-Chu Kiang \\ University of Massachusetts, Boston \\ Dr. Kevin K. Kumashiro \\ University of Illinois, Chicago \\ Dr. Stacey Lee \\ University of Wisconsin, Madison \\ Dr. David Chanpannha Ley \\ Montgomery County Public Schools \\ Dr. Sue Needham \\ California State University, Dominguez Hills \\ Dr. Bic Ngo \\ University of Wisconsin-Madison \\ Dr. Max Niedzwiecki \\ Rights Working Group \\ Dr. Leakhena Nou \\ California State University, Long Beach \\ Dr. Clara Park \\ California State University, Northridge \\ Dr. Mark Pfeifer \\ Texas A\&M University, Corpus Christi \\ Dr. Loan T. Phan \\ University of New Hampshire \\ Dr. Bounlieng Phommasouvanh \\ Minnesota Department of Education
}

\author{
Dr. Karen Quintiliani \\ California State University, Long Beach \\ Dr. Kalyani Rai \\ University of Wisconsin, Milwaukee \\ Dr. Fay Shin \\ California State University, Long Beach \\ Dr. Nancy J. Smith-Hefner \\ Boston University \\ Dr. Yer J. Thao \\ Portland State University \\ Dr. Myluong Tran \\ San Diego State University \\ Dr. Khatharya Um \\ University of California, Berkeley \\ Dr. Linda Trinh Vo \\ University of California, Irvine \\ Dr. Terrence G. Wiley \\ Arizona State University \\ Dr. Zha Blong Xiong \\ University of Minnesota \\ Dr. Kou Yang \\ California State University, Stanislaus
}

\title{
Doctoral Student \\ Editorial Review Board
}

\author{
Keo Chea \\ University of Pennsylvania \\ Vichet Chhuon \\ University of California, Santa Barbara \\ Loan Dao \\ University of California, Berkeley \\ Annie BichLoan Duong \\ San Joaquin County Office of Education \\ Ha Lam \\ Arizona State University \\ Vanna Som \\ Harvard University
}

\author{
Giang Tang \\ University of Minnesota \\ Layheng Ting \\ State University of New York, Albany \\ Loan Tran \\ University of California, Santa Barbara \\ Phitsamay Sychitkokhong Uy \\ Harvard University \\ Yang Sao Xiong \\ University of California, Los Angeles
}

